\title{
Plasmid DNA delivery using cell-penetrating peptide foldamers composed of Arg-Arg-Aib repeating sequences
}

Makoto Oba $^{\dagger^{*}}$, Yurika Ito ${ }^{\dagger}$, Tomohiro Umeno ${ }^{\dagger}$, Takuma Kato ${ }^{\dagger \dagger}$, Masakazu Tanaka ${ }^{\dagger}$

${ }^{\dagger}$ Graduate School of Biomedical Sciences, Nagasaki University, 1-14 Bunkyo-machi, Nagasaki 852-8521, Japan

†Osaka University of Pharmaceutical Sciences, 40-20-1 Nasahara, Takatsuki, Osaka 569-1094, Japan

*To whom correspondence should be addressed:

Makoto Oba

E-mail:moba@nagasaki-u.ac.jp 
Table of Contents

Figure S1

Figure S2

Figure S3

S10

Figure S4

S11 
(a) Peptide 1: CF-Gly-L-Arg-L-Arg-Aib-NH 2

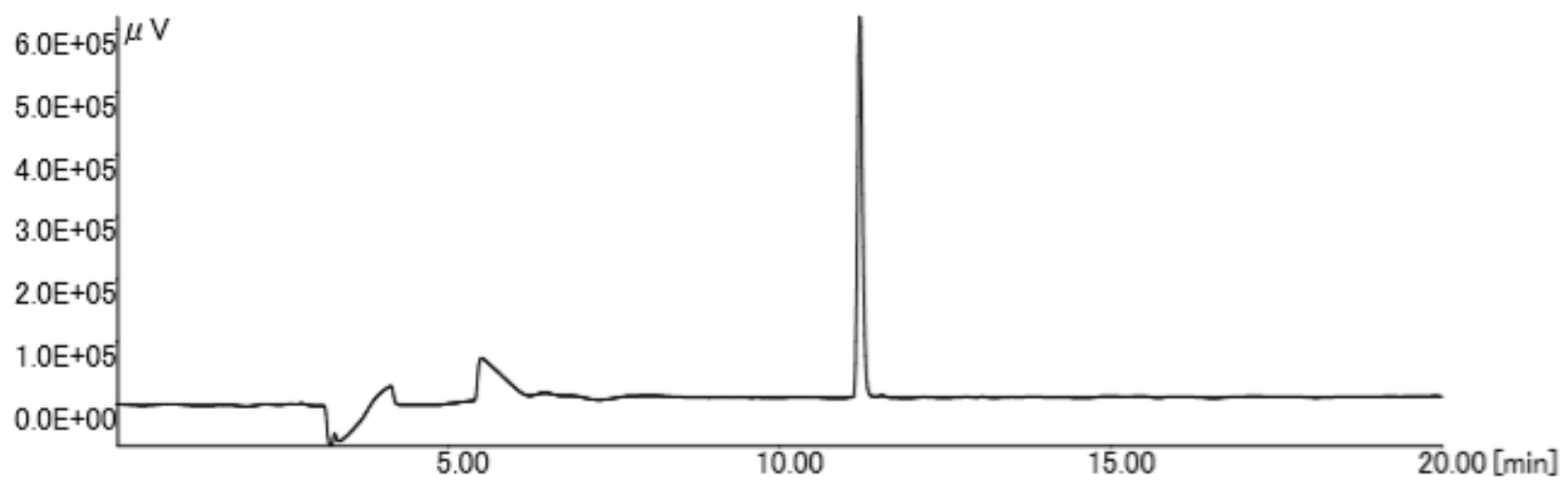

MALDI-TOF MS: $m / z$ calcd for $\mathrm{C}_{39} \mathrm{H}_{48} \mathrm{~N}_{11} \mathrm{O}_{10}[\mathrm{M}+\mathrm{H}]^{+} 830.36$; found 830.22

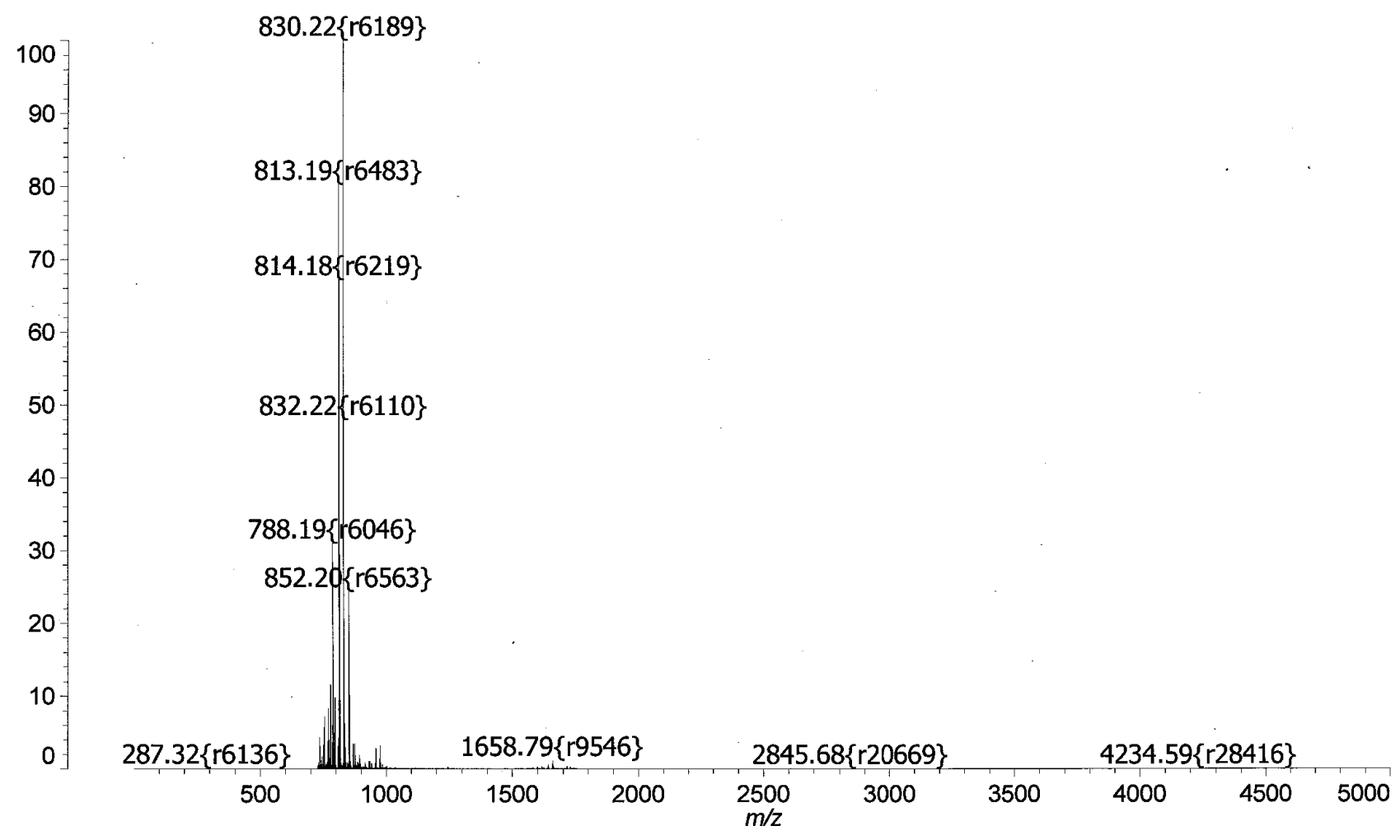


(b) Peptide 2: CF-Gly-(L-Arg-L-Arg-Aib) ${ }_{2}-\mathrm{NH}_{2}$

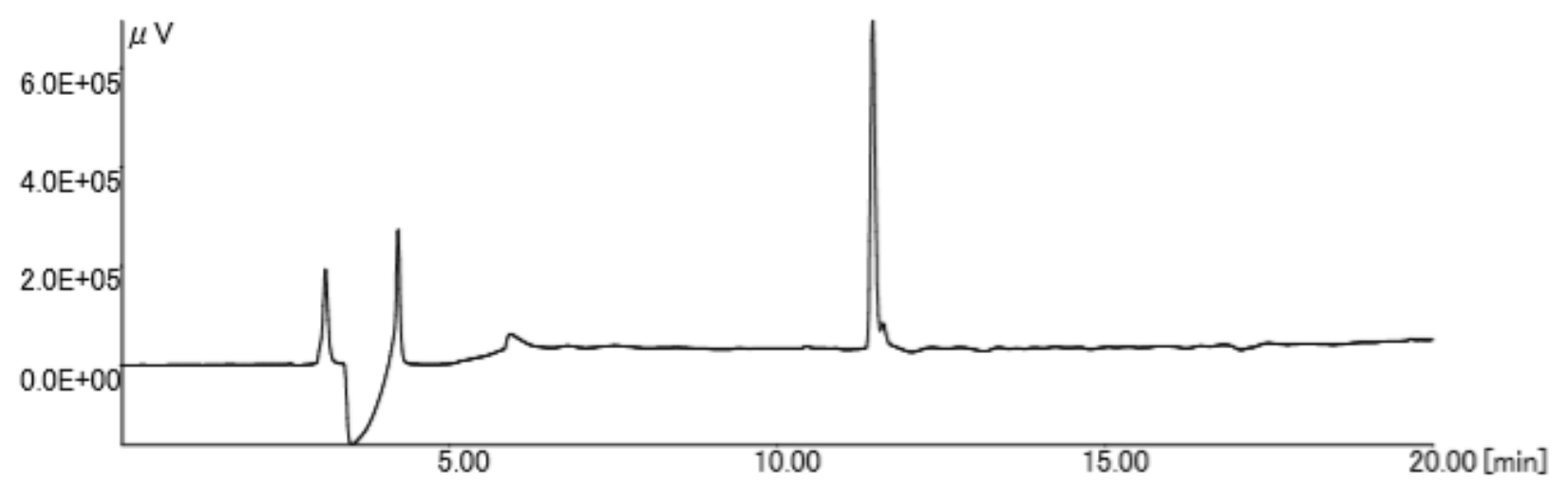

MALDI-TOF MS: $m / z$ calcd for $\mathrm{C}_{55} \mathrm{H}_{79} \mathrm{~N}_{20} \mathrm{O}_{13}[\mathrm{M}+\mathrm{H}]^{+}$1227.61; found 1227.59

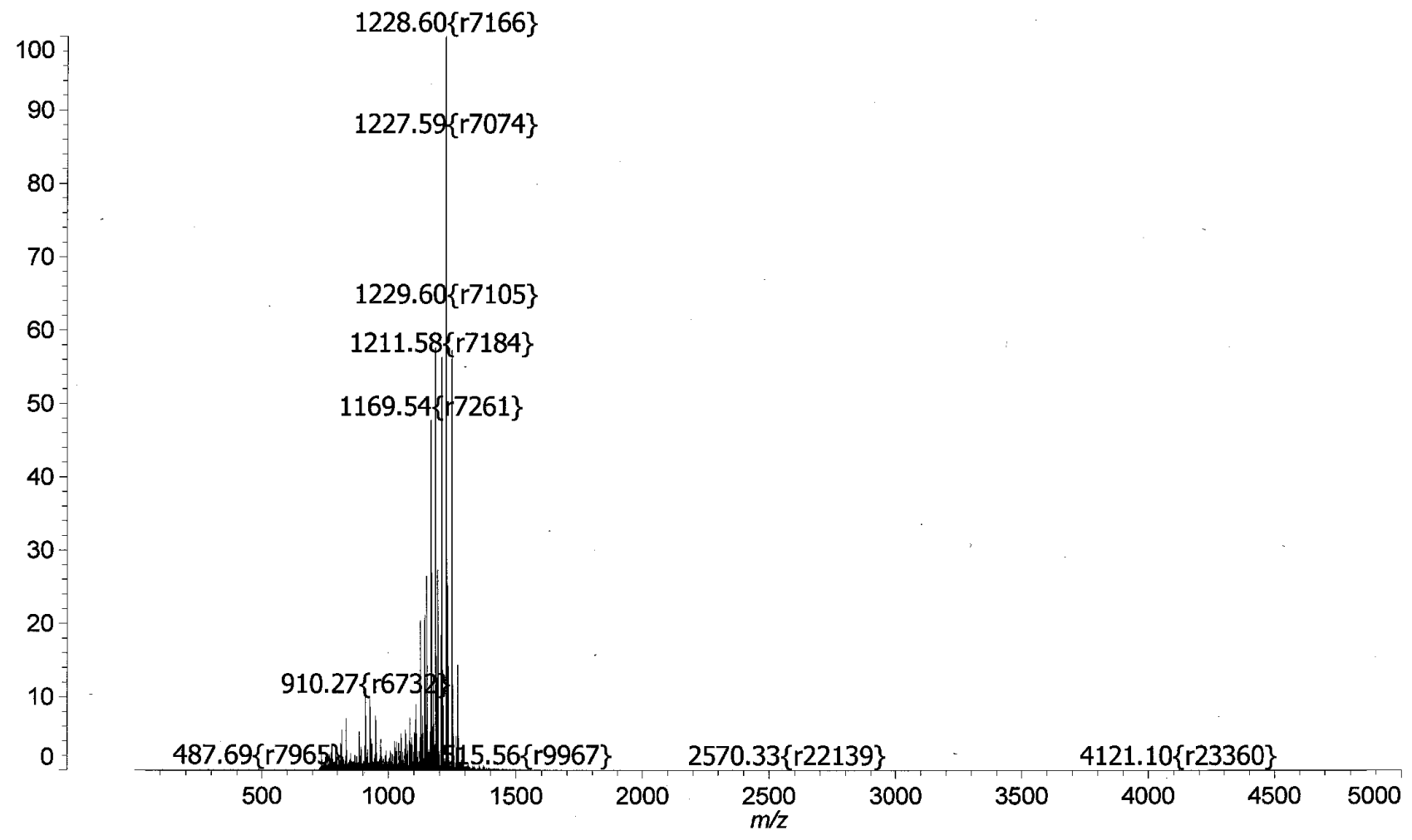


(c) Peptide 3: CF-Gly-(L-Arg-L-Arg-Aib) ${ }_{3}-\mathrm{NH}_{2}$

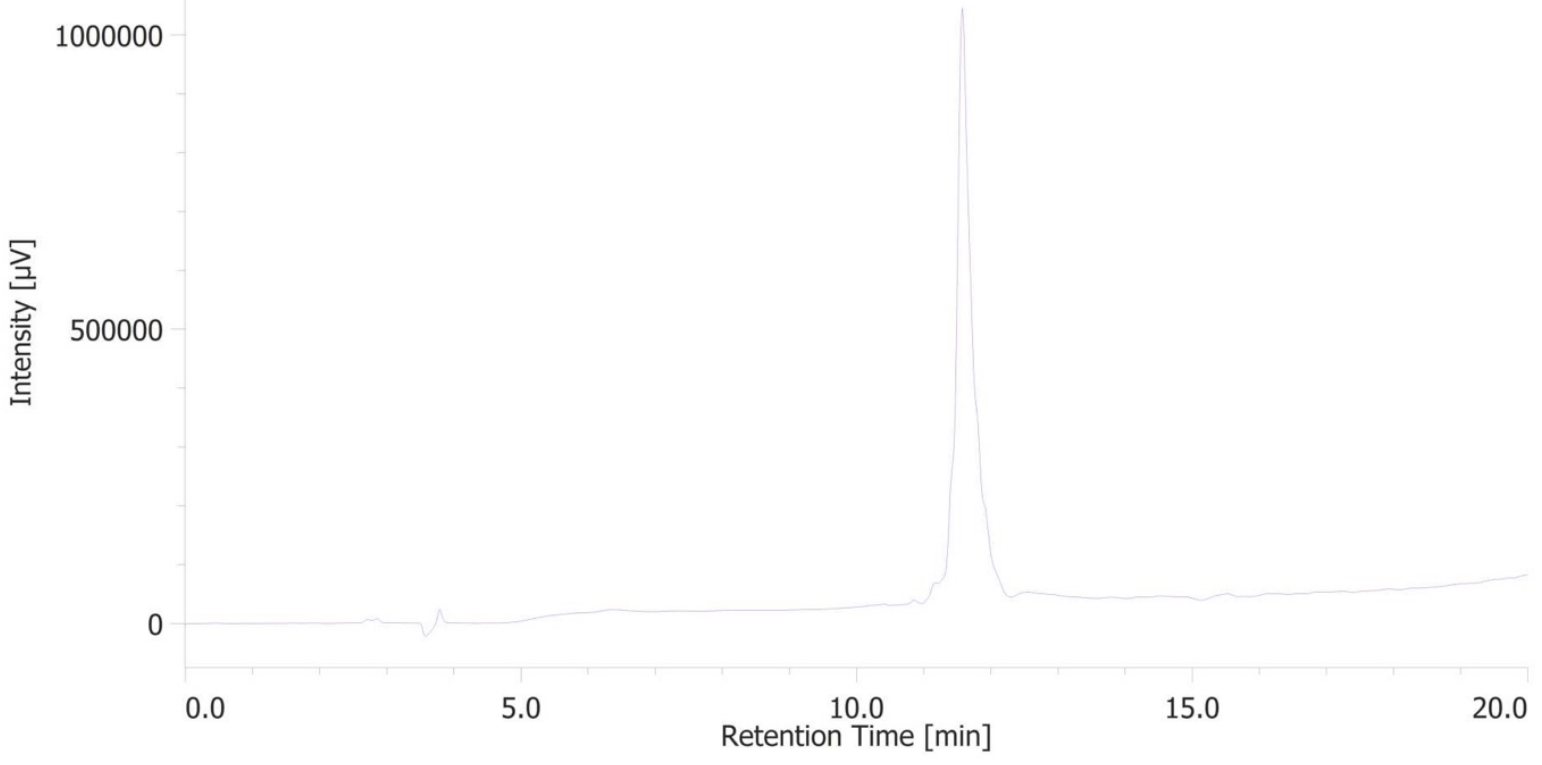

MALDI-TOF MS: $m / z$ calcd for $\mathrm{C}_{71} \mathrm{H}_{110} \mathrm{~N}_{29} \mathrm{O}_{16}[\mathrm{M}+\mathrm{H}]^{+} 1624.87$; found 1626.83

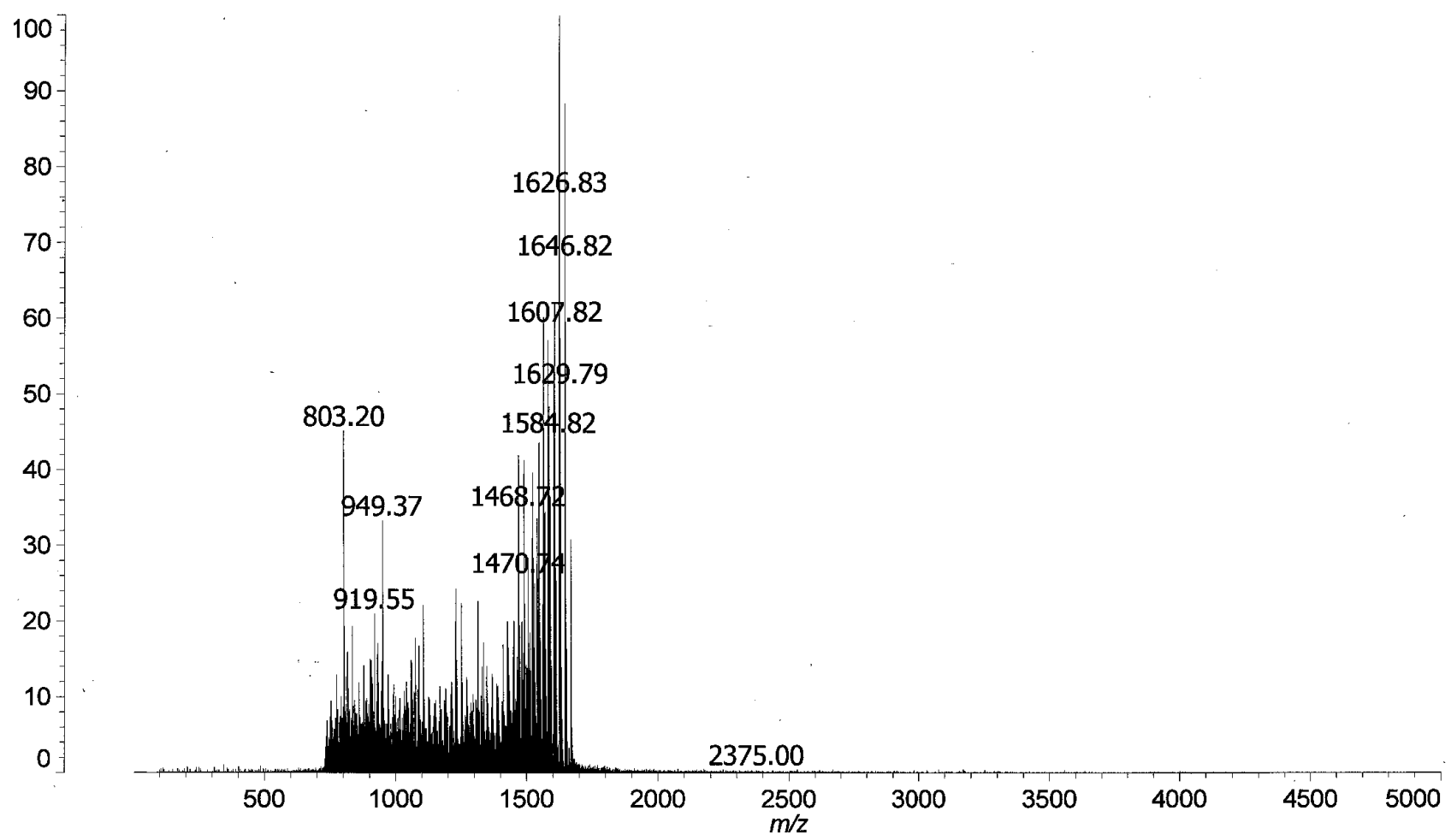


(d) Peptide 4: CF-Gly-(L-Arg-L-Arg-Aib) $)_{4}-\mathrm{NH}_{2}$

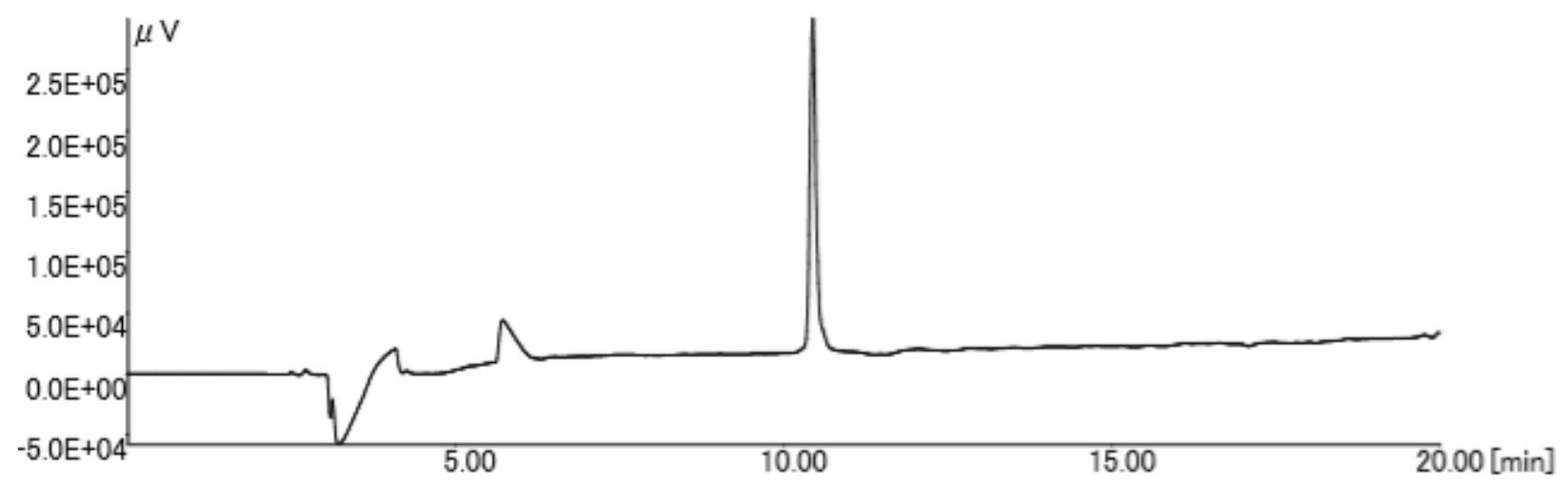

MALDI-TOF MS: $m / z$ calcd for $\mathrm{C}_{87} \mathrm{H}_{141} \mathrm{~N}_{38} \mathrm{O}_{19}[\mathrm{M}+\mathrm{H}]^{+}$2022.12; found 2022.77

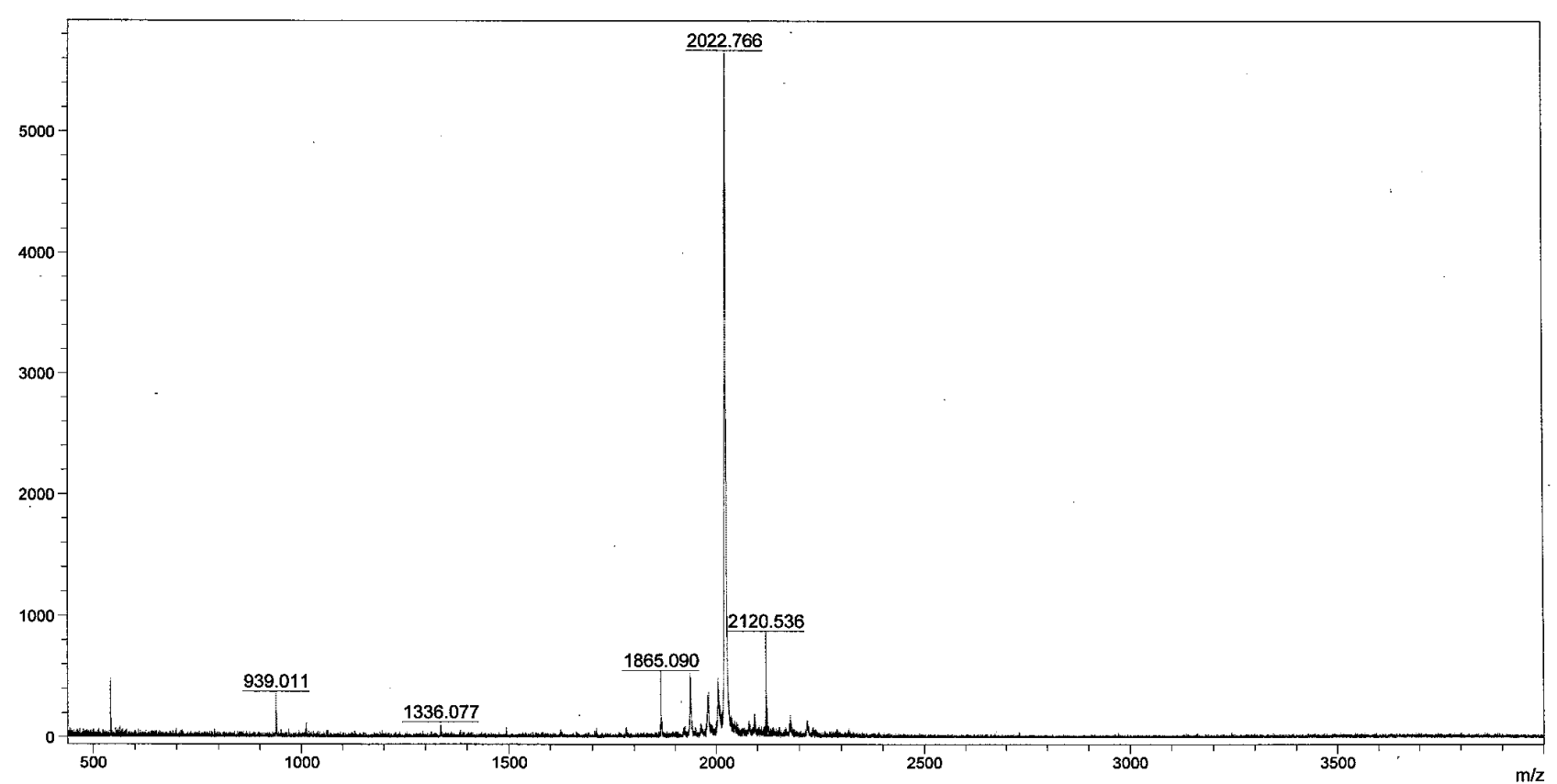


(e) Peptide 5: CF-Gly-(L-Arg-L-Arg-Aib) ${ }_{5}-\mathrm{NH}_{2}$

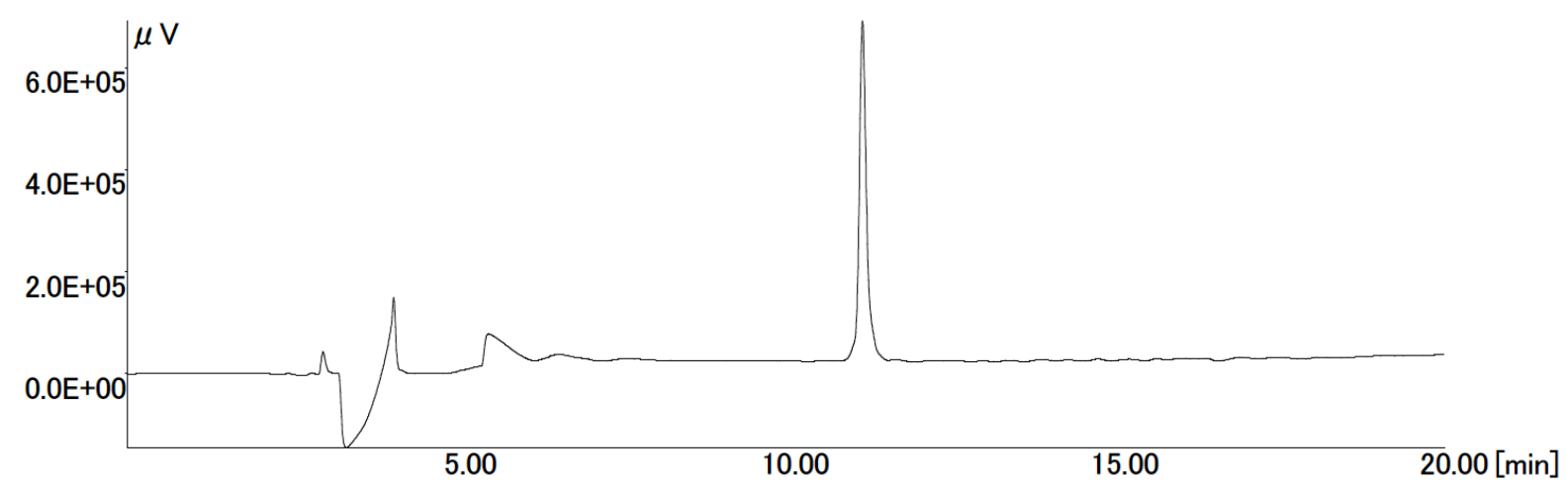

MALDI-TOF MS: $m / z$ calcd for $\mathrm{C}_{103} \mathrm{H}_{172} \mathrm{~N}_{47} \mathrm{O}_{22}[\mathrm{M}+\mathrm{H}]^{+} 2419.38$; found 2420.97

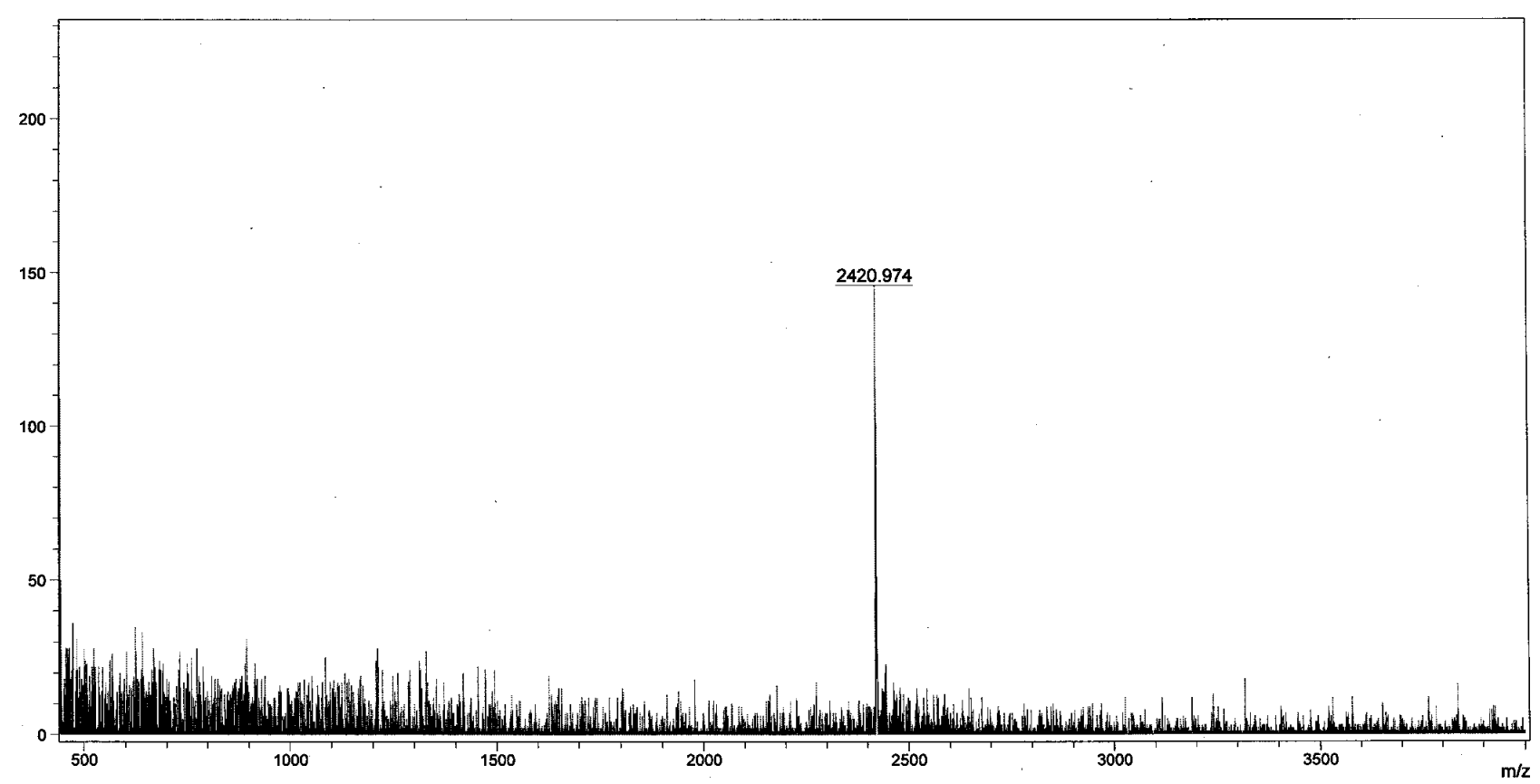


(f) Peptide 6: CF-Gly-(L-Arg-L-Arg-Aib) ${ }_{6}-\mathrm{NH}_{2}$

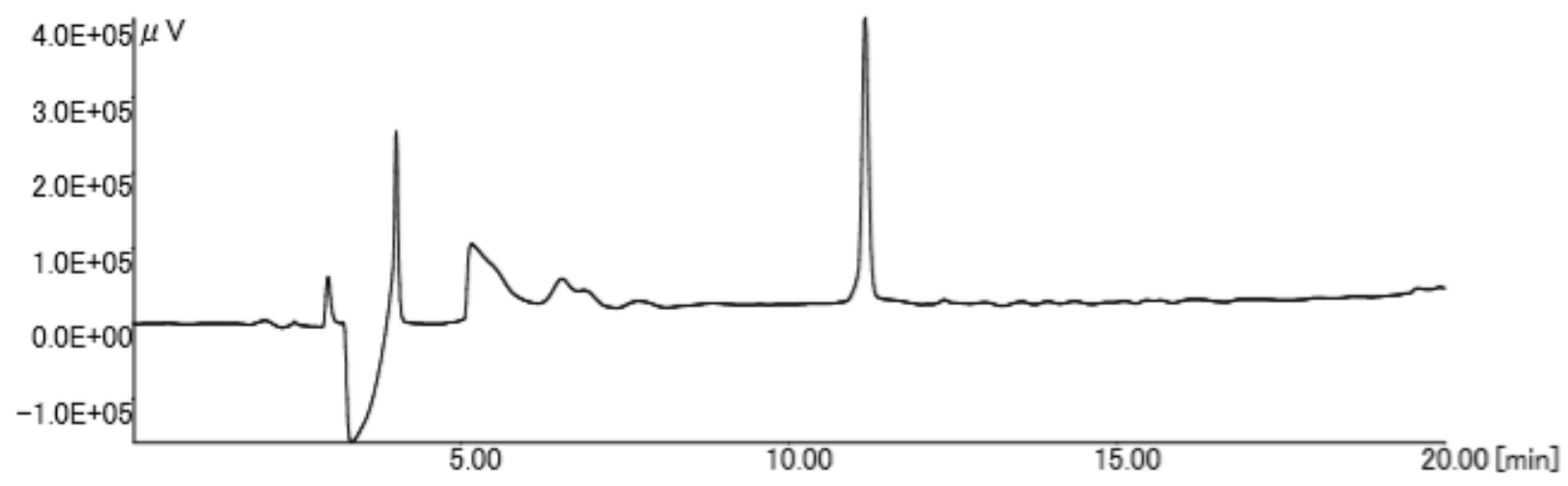

MALDI-TOF MS: $m / z$ calcd for $\mathrm{C}_{119} \mathrm{H}_{203} \mathrm{~N}_{56} \mathrm{O}_{25}[\mathrm{M}+\mathrm{H}]^{+}$2816.63; found 2818.54

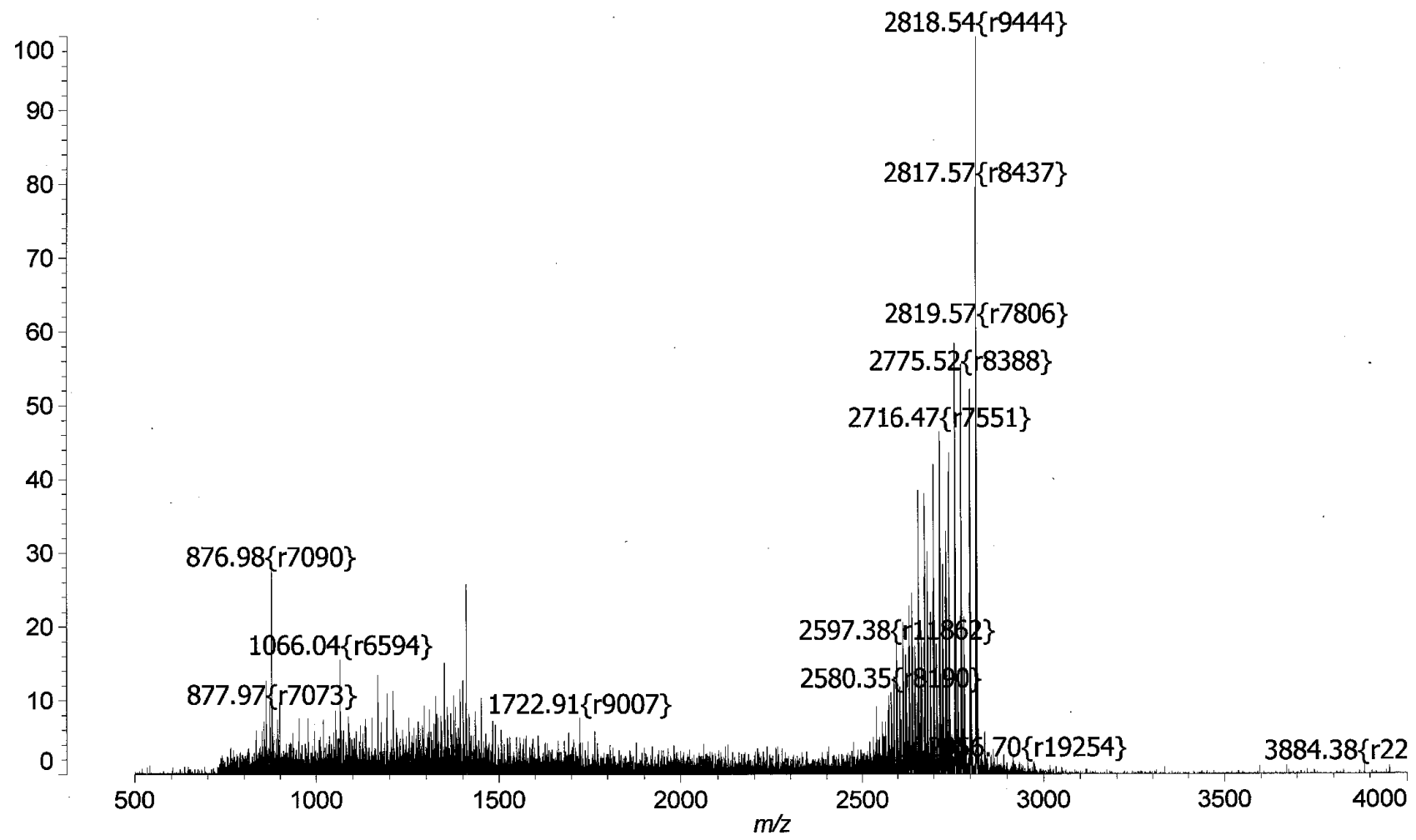

Figure S1. HPLC charts and MALDI-TOF MS spectra of peptides 1-6. 
(a)

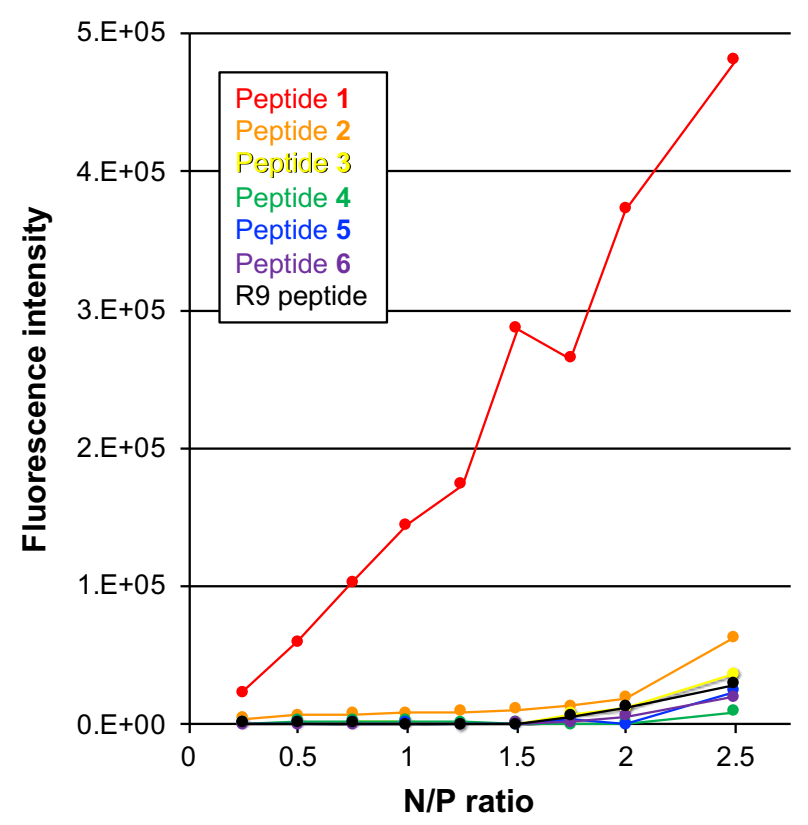

(b)

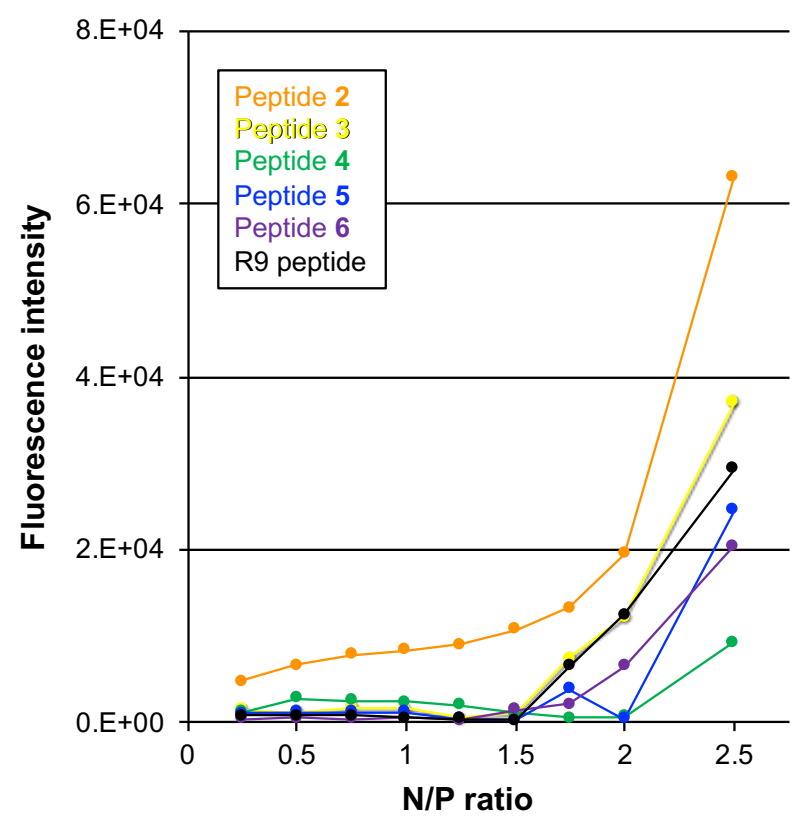

Figure S2. Fluorescence intensities of peptide/pDNA complex solutions at various N/P ratios. (a) All peptides. (b) Peptides except for peptide $\mathbf{1}$ 
(a) Huh-7 cells

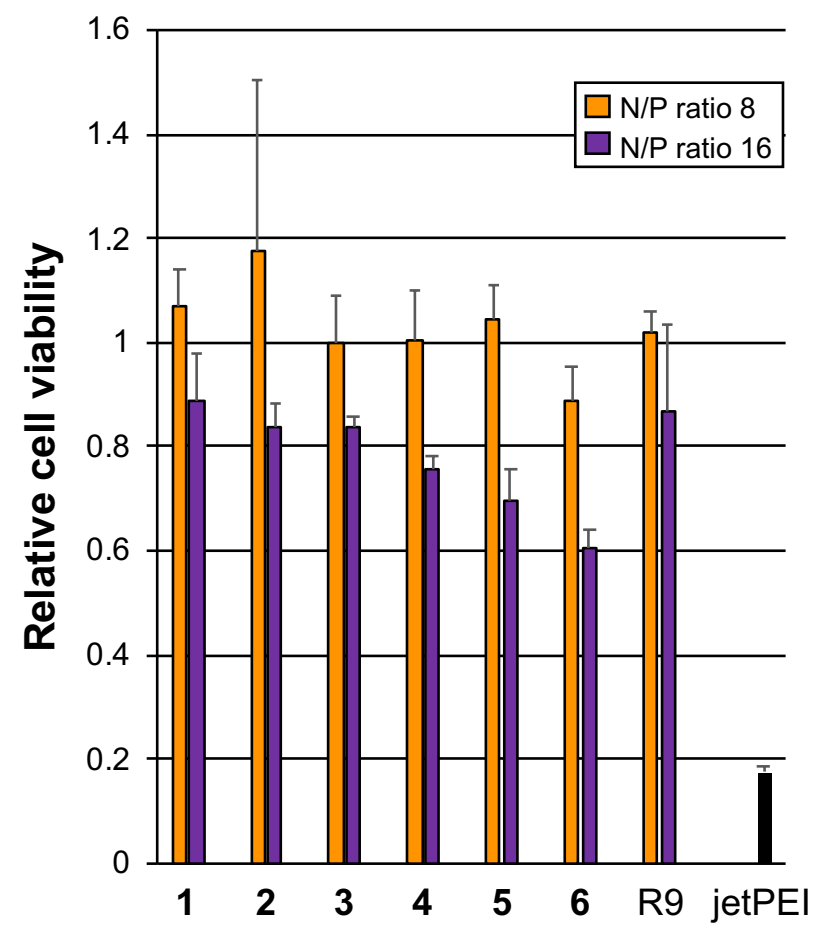

(b) HeLa cells

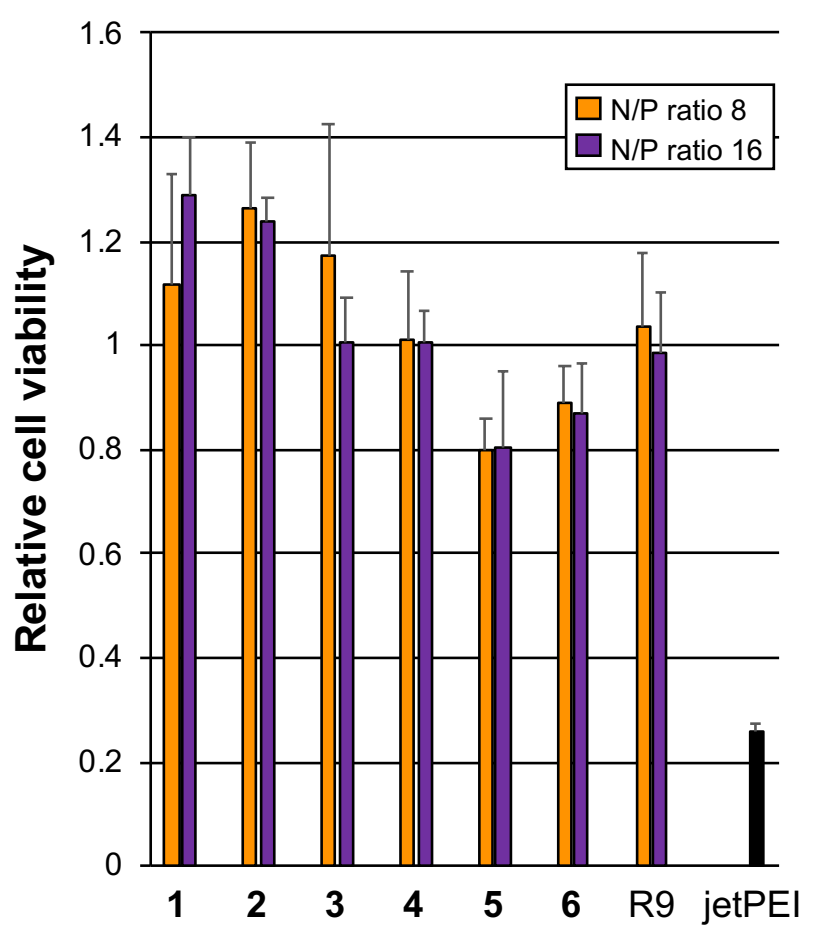

Figure S3. Cell viabilities of Huh-7 cells (a) and HeLa cells (b) treated with peptide/pDNA complexes at $\mathrm{N} / \mathrm{P}$ ratios $=8$ and 16 , and jetPEI/pDNA complexes. Error bars represent the standard deviation, $\mathrm{n}=4$. 


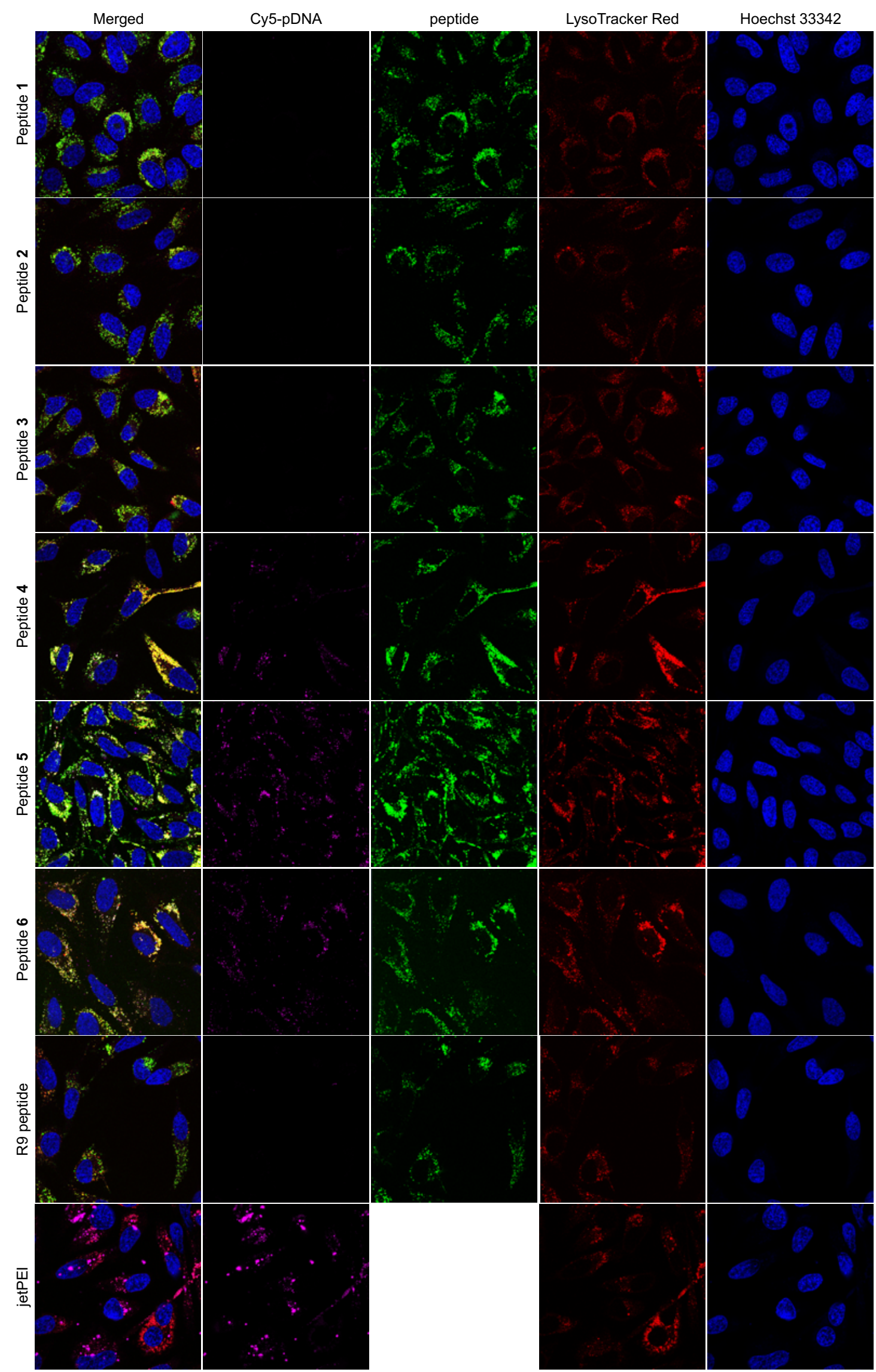

Figure S4. Intracellular distribution of Cy5-pDNA (magenta) with peptides (green) $(\mathrm{N} / \mathrm{P}$ ratio $=8)$ and jetPEI against HeLa cells. Acidic late endosomes/lysosomes and nuclei were stained with LysoTracker Red (red) and Hoechst 33342 (blue). 